\title{
Prescription opioid injection among young people who inject drugs in New York City: a mixed-methods description and associations with hepatitis $C$ virus infection and overdose
}

Pedro Mateu-Gelabert ${ }^{1 *}$, Honoria Guarino ${ }^{1}$, Jon E. Zibbell ${ }^{2}$, Jennifer Teubl ${ }^{3}$, Chunki Fong ${ }^{1}$, Elizabeth Goodbody ${ }^{1}$, Brian Edlin ${ }^{4}$, Carli Salvati ${ }^{1}$ and Samuel R. Friedman ${ }^{5}$

\begin{abstract}
Aim: Evidence is emerging that prescription opioid (PO) injection is associated with increased health risks. This mixed-methods study compares the mechanics of PO and heroin injection and examines the demographic and drug-related correlates of lifetime PO injection in a sample of young people who inject drugs (PWID) in New York City (NYC).

Methods: Qualitative analysis of 46 semi-structured interviews with young adult opioid users ages 18-32. Interview segments describing PO injection were analyzed for common themes. Quantitative analysis of structured interviews with 539 young adult opioid users ages 18-29 recruited via respondent-driven sampling (RDS). Analyses are based on the subsample of 353 participants (65\%) who reported having ever injected drugs. All variables were assessed via self-report, except hepatitis $C$ virus status, which was established via rapid antibody testing.

Results: Participants described injecting POs and reported that preparing abuse-deterrent pills for injection is especially cumbersome, requiring extended manipulation and large amounts of water. Injecting POs, in contrast to injecting heroin, requires repeated injections per injection episode. Among RDS-recruited participants, the majority of injectors reported injecting POs, sporadically (33\%) or regularly (26\%), but often infrequently ( $\leq 7$ days/month). In separate multivariable analyses controlling for syringe- and cooker-sharing, ever injecting POs was a significant predictor of testing HCV antibody-positive ( $A O R=2.97$ ) and lifetime experience of non-fatal overdose (AOR $=2.51$ ). Ever injecting POs was independently associated with lifetime homelessness $(A O R=2.93)$ and having grown up in a middle-income $(\$ 51,000-100,000 /$ year vs. $\leq \$ 50,000$ / year; $A O R=1.86$ ) or a high-income household ( $>\$ 100,000 /$ year vs. $\leq \$ 50,000 /$ year; $A O R=2.54$ ).

(Continued on next page)
\end{abstract}

\footnotetext{
* Correspondence: pedro.mateu-gelabert@sph.cuny.edu

${ }^{1}$ CUNY Graduate School of Public Health and Health Policy, Institute for Implementation Science in Population Health (ISPH), 55 West 125th Street, New York, NY 10027, USA

Full list of author information is available at the end of the article
}

(c) The Author(s). 2020 Open Access This article is licensed under a Creative Commons Attribution 4.0 International License, which permits use, sharing, adaptation, distribution and reproduction in any medium or format, as long as you give appropriate credit to the original author(s) and the source, provide a link to the Creative Commons licence, and indicate if changes were made. The images or other third party material in this article are included in the article's Creative Commons licence, unless indicated otherwise in a credit line to the material. If material is not included in the article's Creative Commons licence and your intended use is not permitted by statutory regulation or exceeds the permitted use, you will need to obtain permission directly from the copyright holder. To view a copy of this licence, visit http://creativecommons.org/licenses/by/4.0/ The Creative Commons Public Domain Dedication waiver (http://creativecommons.org/publicdomain/zero/1.0/) applies to the data made available in this article, unless otherwise stated in a credit line to the data. 
(Continued from previous page)

Conclusions: Even in an urban environment like NYC with widespread heroin access, most young PWID have injected POs, although less frequently than heroin. PO injection involves practices that are known to increase risk for blood-borne viral infection (e.g., repeated injections) and predicted testing HCV-positive, as well as overdose. PO injection may also serve as a marker for a subgroup of PWID at elevated risk for multiple drug use-related comorbidities. Programs that provide prevention services to PWID need to tailor harm reduction measures and messaging to the specific practices and harms associated with the injection of POs.

Keywords: Prescription opioid misuse, Prescription opioid injection, Young PWID, Heroin, Drug overdose, Hepatitis C virus (HCV) infection

\section{Introduction}

Prescription opioid (PO) injection is on the rise in the USA. Among a nationally representative sample of people 12 years or older, the prevalence of lifetime PO injection increased from 1.6 per 1000 in 2003-2005 to 2.7 per 1000 in 2012-2014 [1]. This trend is also reflected in US POrelated treatment admissions, with PO injection among new admissions to substance use treatment rising from $11.7 \%$ in 2004 to $18.1 \%$ in 2013 [2].

The prevalence of PO injection among non-treatmentseeking samples of drug users varies across regions of the USA. In rural Kentucky, $89 \%$ of people who inject drugs (PWID) in a cohort sample reported injecting POs in their lifetime [3], while a study of young, streetinvolved PWID in urban New York City (NYC) and Los Angeles who reported recent nonmedical PO use found that $72 \%$ reported having ever injected POs ("lifetime" PO injection) [4]. In Scott County, Indiana, the site of a large HIV outbreak among PWID in 2015, the vast majority of HIV-infected PWID reported the current injection of extended-release oxymorphone $\left(\mathrm{OpanaER}^{\circ}\right)$ as their primary drug of choice [5]. In contrast, a study of young PWID in rural New York State who misused POs [6] reported lower rates of current PO injection (58\%). Differences in study design and PO availability across regions are likely influencing the reported variability in PO injection rates.

Beyond the risks associated with injection drug use in general, which include exposure to blood-borne viruses (such as HIV and hepatitis $\mathrm{C}$ virus [HCV]), as well as bacterial infections related to injecting in unsterile environments [7], the injection of PO pills in particular has been shown to be independently associated with HCV infection in samples of PWID [6,7]. Several recent studies have found that PWID who report injecting POs have an increased likelihood of being $\mathrm{HCV}$ antibody-positive relative to PWID who inject heroin only $[3,4,6,8,9]$. A prospective study of drug-using street youth, however, found in a multivariate model that $\mathrm{PO}$ injection was not a significant predictor of HCV incidence [10].

While injection-related viral transmission risk has largely been associated with the sharing of contaminated injection equipment (e.g., syringes and cookers), the risks associated with $\mathrm{PO}$ injection may occur at each stage of the process involved in preparing and injecting opioid pills, including pill crushing, the use of extra water (relative to heroin injection), sharing "rinse shots," and other practices that place pill injectors at increased vulnerability to viral exposure [8]. Most recently, the cumbersome and lengthy process of preparing and injecting POs has been shown to often involve multiple injections per injection episode which may contribute to the development of new, blood-borne viral transmission pathways $[11,12]$.

In a systematic review of health outcomes associated with PO injection, Lake and Kennedy [9] report that PO injection has also been found to be correlated with recent non-fatal overdose among women (not men) in a cohort study of PWID recruited through street outreach [13] and to have marginally significant associations with lifetime non-fatal overdose among street-recruited rural drug users [14]. One study found that PO injection among street-recruited youth who used POs was correlated with lifetime overdose in bivariate analyses, yet did not remain significant in multivariable analysis [15], while other studies among street-recruited [16, 17] and syringe exchange program-recruited opioid users [18] did not find any significant association between PO injection and recent non-fatal overdose.

While prior studies have described the mechanics of PO injection and have found significant associations between PO injection and HCV-positive status or overdose, in this paper, we expand on this literature by using a mixedmethods design that allows for a more comprehensive understanding of PO injection. Specifically, we employ qualitative interview data describing the mechanics of preparing and injecting POs to help interpret and contextualize our quantitative findings addressing the research question: "What are the associations between PO injection and HCV infection and unintentional opioid overdose?" We also present additional quantitative data to compare patterns of heroin injection vs. PO injection in the context of young people's opioid use trajectories. Furthermore, our distinctive study samples of sociodemographically diverse, urban 
young adults who were actively using opioids, but were not necessarily street-involved, help fill an important gap in our understanding of the opioid injection patterns of young opioid consumers living in American cities.

\section{Methods}

This mixed-methods paper presents select findings from a larger study that assessed the drug use practices and health risks of young adults in NYC who use opioids (including the nonmedical use of POs and/or heroin use). The current analyses focus on patterns and correlates of PO injection in two samples of young adults who use opioids. Qualitative data from one sample are presented to characterize the mechanics used to prepare and inject POs. Quotations from face-to-face interviews with young people who inject POs and heroin are presented to identify behaviors and techniques specific to the way PO pills are prepared and injected in order to differentiate them from the techniques used with heroin and other illicit drugs. Quantitative data from a second sample are used to establish the prevalence of $\mathrm{PO}$ injection among the subset of participants who reported having ever injected drugs and the frequency with which they injected POs and heroin. Quantitative data also establish how PO injection fits into participants' broader opioid use trajectories and the associations between PO injection and key sociodemographic (e.g., socioeconomic status) and drug use-related (e.g., having ever overdosed) variables.

\section{Qualitative data collection and analysis}

The qualitative portion of the analysis is based on data from 46 participants (ages 18-32) who were interviewed in the formative phase of the study. Participants lived in one of the five boroughs of NYC, reported having used POs for nonmedical reasons at least once in their lifetime (most reported use in the past 30 days), and spoke English or Spanish. Participants were referred by service providers (e.g., drug treatment programs, youth-focused harm reduction services), other research projects, or via chain-referral from other participants. Further details on the 46 participants included in the qualitative sample are reported elsewhere $[19,20]$.

Interviews were semi-structured, digitally audio-recorded, and lasted approximately $90 \mathrm{~min}$. Interviews were transcribed verbatim, and the software program ATLAS.ti was used to facilitate the coding and analysis of qualitative data. Following a semantic thematic analysis approach [21, 22], the explicit meaning of participants' words served as the basis for thematic coding. Interview transcripts were read to identify all quotes related to $\mathrm{PO}$ and heroin injection practices. Using these quotes, themes were identified on the basis of recurring patterns through multiple participants' accounts. The themes established in this analysis were often related to the relatively more involved process of preparing and injecting an opioid pill (vs. injecting heroin). Themes corresponding to the general process of preparing a $\mathrm{PO}$ as opposed to heroin for injection included the "need for more water" and "applying heat." Themes that were specific to injecting POs vs. heroin included "using larger syringes," "multiple injections per injection episode (MIPIE)," and/or "reusing cottons."

All names have been changed to pseudonyms to protect participants' confidentiality, and some quotations have been slightly edited for clarity.

\section{Quantitative data collection}

For the quantitative phase of the study, a different sample was recruited using respondent-driven sampling (RDS), a form of chain-referral sampling designed to engage hard-to-reach populations that uses participants' personal network connections to drive recruitment. This method, which reaches people who may not frequent street settings, may yield a more representative sample than street recruitment. Using this method, an initial set of 20 "seeds" was directly recruited by research staff from referrals by harm reduction services, drug treatment programs, participants in the qualitative component, and other research projects. These participants completed structured assessments and were invited to refer up to three eligible peers from among their opioid-using contacts to participate in the study. This process was repeated with the seeds' recruits and for successive sample waves leading to a total of 539 participants recruited from August 2014 to April 2016. Eligibility criteria included nonmedical use of POs and/ or heroin use 3 or more times in the past 30 days, current residence in NYC, 18-29 years old, Englishspeaking, and the ability to provide informed consent. Participants were compensated $\$ 60.00$ USD for completing the interview, and an additional incentive was provided for each eligible participant they referred. Further details on the RDS methods used in this study are reported in Mateu-Gelabert et al. [23].

Participants completed a computer-assisted, interviewerassisted structured assessment lasting $90-120 \mathrm{~min}$. The instrument included sociodemographic and behavioral questions (951 questions organized in 27 sections) related to the following: substance use and drug injection history and current practices, injection-related $\mathrm{HIV} / \mathrm{HCV}$ risk behavior, opioid use and injection networks, and lifetime and recent overdose experiences, among other topics. The present analysis is based on the subset of the total sample who reported injecting any drug for nonmedical purposes at any point in their lifetime $(n=353 / 539,66 \%)$. Because 6 participants did not respond to the questions specific to $\mathrm{PO}$ injection, analyses requiring these variables are based on a sample of 347 . 


\section{Variable definitions}

In structured assessments and statistical analyses, nonmedical use of POs was defined as the "use of POs not prescribed for the respondent or use of these drugs only for the experience or feeling they caused" [24]. PO injection was defined as injecting any PO intended for oral intake. For the variables included in this report, "regular" injection was defined as injecting a given drug three or more times a week for at least 1 month. "Sporadic" injection was defined having injected a given drug at least once but not having done so regularly. Duration of regular injection of POs and heroin was measured by the number of months a participant had regularly injected the drug in their lifetime. The frequency of PO and heroin injection in the past 30 days was measured by the number of days each drug was injected. "Non-fatal overdose" was defined as any event in which a participant "lost consciousness, stopped breathing or was unresponsive as a result of drug use." Opioid use trajectory variables included ages at first nonmedical PO use, first heroin use, first heroin injection, and first PO injection. Two injection risk variables were assessed, sharing syringes and sharing cookers, measured by the number of people with whom the sharing took place in the past 12 months. Sharing syringes was defined as receiving a syringe that had been previously used by someone else. Sharing cookers was defined as using a cooker someone else had previously used or using it simultaneously with someone else. All variables were based on self-report data except HCV antibody status, which was assessed with point-of-care rapid testing using the OraQuick Advance Rapid HCV Antibody Test (manufactured by OraSure Technologies, Inc., Bethlehem, PA).

\section{Quantitative analyses}

All statistical analyses were conducted in the program $\mathrm{R}$, versions 3.2.2 and 3.2.4 ( $\mathrm{R}$ Core team, 2015) and IBM SPSS 25. For bivariable and multivariable analyses, response categories for lifetime PO injection were collapsed into two groups-never injected POs and ever injected POs-after a chi-squared test indicated a significant effect for several variables. First, binary associations of the three variables of interest ( $\mathrm{HCV}$-positive status, lifetime overdose, and lifetime PO injection) with a series of sociodemographic (gender, race/ethnicity, household income growing up, lifetime homelessness) and injection risk variables (syringe- and cooker-sharing in the past 12 months) were computed. Log ratios and $p$ values were computed for all binary associations using a Wald chi-squared test, with a 95\% confidence interval [25].. Following the strategy described in Hosmer et al., blocks of variables with $p$ $<0.25$ in bivariable analyses were then included in separate multivariable models for each of the three dependent variables of interest [26-28]. Multivariable models were run using generalized linear model ( $\mathrm{R}$ version 3.2.4, glm 4.13-19), and adjusted odds ratios were computed using the model estimate. Results were verified with logistic regression in SPSS. Associations of PO injection with $\mathrm{HCV}$-positive status and with non-fatal overdose were determined by separate multivariable models with HCVpositive status and non-fatal overdose as dependent variables, respectively. Potential sociodemographic predictors of lifetime PO injection were determined by a third multivariable model with PO injection as a dependent variable.

\section{Results}

\section{Qualitative findings}

Of the 46 qualitative interviewees, 27 were male, $18 \mathrm{fe}$ male, and one transgender female. Participants were 25.3 years old on average $(\mathrm{SD}=3.9$ years; range $=18-32$ years). In response to interview questions regarding participants' opioid use, some participants provided detailed descriptions of their PO injection practices.

Participants described multiple methods for converting solid pills into injectable solutions. Each type of preparation method was tailored to the specific type and formulation of opioid. Participants preferred immediaterelease (IR) oxycodone pills because they can be easily crushed and dissolved in water without the cumbersome process of trying to circumvent extended-release and/or abuse-deterrent technology. Respondents described the difficulties involved in trying to separate the opioid from the pill's fillers and binders. Their stated goal was to maximize the amount of overall pill content that dissolved in water so the drug was suspended in a solution that was watery-enough to be drawn into a syringe. Bruce, a 26-year-old white male, described the method he used to prepare blue oxycodone pills for injection:

I'll put the whole pill in there [in a cooker]. I'll have a $1 \mathrm{cc}$ syringe with at least 75 units of water in it, preferably warmish. I'll squirt half on, I'll take the back of a plunger of another needle...start crushing it as fine as I can, rest of the water mix it up with, again, the plunger, fold it, heat it for maybe five full seconds until your finger starts to hurt...I see the actual sediment, like the binders, you know it separates, you've got this pile of gook, and then you've got this blue water, it looks like a Smurf got melted. Throw in the cotton, and I suck it up, and then I'll move the cotton around 'cause a lot of it's [the drug] stuck in the actual gel of the residue.

Bruce's description is fairly representative of the techniques interviewees reported using to prepare opioid pills for injection. Converting extended-release and/or abuse-deterrent opioid formulations into an aqueous solution that is watery-enough to be drawn into a syringe 
typically requires a larger amount of water relative to the volume needed to dissolve the powder heroin available in NYC. The objective need for more water is of critical importance because the volume of the resulting pillbased solution is too large $(>0.5 \mathrm{cc})$ for the common syringe used by PWID in NYC $(0.5 \mathrm{cc})$ to hold. To inject an opioid solution whose volume is greater than $0.5 \mathrm{cc}$ requires a person to either administer multiple injections in a single injection episode using a 0.5 -cc syringe [11, $12]$ or to use a larger syringe $(\geq 1.0 \mathrm{cc})$ to inject the entire solution in a single injection.

Respondents also reported the need for heat when dissolving most opioid pill formulations, either heating the cooker with the flame from a lighter or heating the pill in a microwave or conventional oven. After adding water to the pill and adding heat, Bruce described the resulting material as viscous, referring to it as "gook," and reported needing to perform additional steps to fully dissolve the pill. He described an intense and repeated process of manipulation whereby a water-soaked pill is repetitively crushed with the flat top of a syringe plunger while extra water is added and the filter is continuously repositioned in the cooker to create a solution that is watery enough to be effectively filtered and drawn into a syringe.

Some participants described reusing cottons that had been previously used by peers to filter PO-containing solutions in order to access the drug residue contained within them. In addition, participants also reported preparing an additional drug solution from the pill residue that remained in the cooker after the original solution was injected, despite being aware of the reduced opioid content associated with residue. For example, William, a 28-year-old, white male, stated:

I'll do another shot out of it [the residue]. I'll put water on it and I'll mix it up again, and I'll get a small rush out of it, not a lot but some... I'll do my shot and then I'll put water in it and I'll mix it up and I'll do it right after I do the shot. I'll do two shots at once, yeah, or one right after the other.

As evident from William's comment, and in contrast to injecting heroin, study participants typically described the injection of POs as more cumbersome and timeconsuming. Dissolving heroin requires less water than extended-release and/or abuse-deterrent PO formulations and thus smaller-volume (e.g., $0.5 \mathrm{cc}$ ) syringes can be used to inject an entire heroin solution in a single injection. Because heroin in NYC is widely available in powder form and readily dissolves in water with little to no heat, needing less than $0.5 \mathrm{cc}$ of water is standard practice. In the following excerpt, Elton, an 18-year-old male of Asian descent, summarizes why he prefers injecting heroin to pills: "As far as the pills go, I feel like it's kind of inefficient. Maybe there is too much powder, doesn't get absorbed fully, but for some reason, I don't get the full rush as if you were shooting heroin."

\section{Quantitative findings}

The sociodemographic characteristics of the subsample of 353 PWID who participated in the study's RDS phase are presented in Table 1. Most participants were male (65\%), White/non-Latino (73\%), and $36 \%$ grew up in households with annual incomes of less than $\$ 51,000)$. However, a considerable minority (23\%) grew up in households with annual incomes of $\$ 101,000$ or more. Thirty-nine percent reported never injecting POs, while 33\% reported injecting POs sporadically, and $26 \%$ reported doing so regularly. In contrast, the vast majority (98\%) had injected heroin and $89 \%$ had done so regularly.

Table 1 Characteristics of RDS-recruited Participants $(n=353)$

\begin{tabular}{|c|c|c|}
\hline Characteristic & Mean (SD) & $\boldsymbol{N}(\%)$ \\
\hline Age & $24(3)$ & \\
\hline \multicolumn{3}{|l|}{ Gender } \\
\hline Male & & $230(65)$ \\
\hline Female & & $119(34)$ \\
\hline Transgender & & $4(1)$ \\
\hline \multicolumn{3}{|l|}{ Race/ethnicity } \\
\hline White & & $259(73)$ \\
\hline Latino/a & & $66(19)$ \\
\hline Non-White and non-Latino/a & & $26(7)$ \\
\hline \multicolumn{3}{|c|}{ Household income growing up (annual) ${ }^{1}$} \\
\hline$\$ 0-\$ 50,000$ & & $126(36)$ \\
\hline$\$ 51,000-\$ 100,000$ & & $116(33)$ \\
\hline$\$ 101,000$ or more & & $81(23)$ \\
\hline Did not respond & & $30(8)$ \\
\hline \multicolumn{3}{|c|}{ Heroin and prescription opioid injection (lifetime) } \\
\hline Never injected POs & & $139(39)$ \\
\hline Injected POs sporadically & & $116(33)$ \\
\hline Injected PO regularly ${ }^{2}$ & & $92(26)$ \\
\hline Never injected heroin & & $5(2)$ \\
\hline Injected heroin sporadically & & $33(9)$ \\
\hline Injected heroin regularly² & & $314(89)$ \\
\hline Ever homeless & & $247(70)$ \\
\hline Ever overdosed & & $197(56)$ \\
\hline HCV antibody-positive & & $105(30)$ \\
\hline
\end{tabular}

This table is based on the 353 participants who reported ever injecting drugs ${ }^{1}$ Thirty participants (9\%) did not respond to the question about household income while growing up. For all other variables, less than $5 \%$ of data are missing

${ }^{2 " R e g u l a r " ~ i n j e c t i o n ~ i s ~ d e f i n e d ~ a s ~ i n j e c t i n g ~} 3$ or more times per week for at least 1 month 
Participants' opioid use histories, drug used at first injection, and frequency of $\mathrm{PO}$ and heroin injection are presented in Table 2. On average, participants' first nonmedical PO use occurred about 4 years prior to any opioid injection and 2.6 years prior to heroin use. Among those who reported ever injecting POs, first PO injection typically occurred shortly after the first heroin injection. Likewise, the drug used at first injection was overwhelmingly heroin (82\%), followed by POs (7\%).

On average, participants had regularly injected heroin for a total of 34.5 months ( $S D=34.9$ ), which is 24.3 months longer than they had regularly injected POs (10.2 months, SD $=20.4)$. A majority $(84 \%)$ reported injecting heroin in the past month, with an average of 18.6 days of heroin injection in the past 30 days. Fewer participants (14\%) had injected POs in the past month, averaging only 5 days of PO injection in the past 30 days (see Table 2).

Table 3 presents the bivariable and multivariable associations of lifetime $\mathrm{PO}$ injection with $\mathrm{HCV}$-positive status when controlling for socio-demographics and injection risk variables. Lifetime homelessness, the number of people with whom the participant shared syringes in the past 12 months, and the number of people with whom the participant shared cookers in the past 12 months were associated with $\mathrm{HCV}$-positive status in bivariable analyses and thus, along with household income growing up which had an omnibus $p$ value $<0.25(p=0.18)$, were entered as covariates in determining the association between PO injection and HCV-positive status [27, 28]. PO injection was found to be associated with HCV-positive status (AOR $2.97,1.50-5.86, p<0.01)$.

Table 4 presents a similar table to Table 3 except with the dependent variable being lifetime experience of nonfatal overdose. The same sociodemographic and injection risk variables associated with HCV-positive status were also found to be associated with non-fatal overdose in bivariable analyses: lifetime homelessness, the number of people with whom the participant shared syringes in the past 12 months, and the number of people with whom the participant shared cookers in the past 12 months. In addition, because the omnibus test for race/ethnicity and for household income growing up had $p$ values of $<0.25$ ( $p=0.17$ and $p=0.18$, respectively), these variables were also included in the model. PO injection was found to be associated with non-fatal overdose (AOR 2.51, 1.47-4.28, $p<0.01$ ) when controlling for these five sociodemographic and injection risk variables.

Table 5 presents the bivariable and multivariable associations of lifetime PO injection with the same series of sociodemographic independent variables. Gender and race/ethnicity were not significantly associated with PO injection in bivariable analyses. Nevertheless, race/ethnicity was included in the multivariable analysis due to its
Table 2 Prescription opioid (PO) and heroin injection history and behavior among young adult PWID $(n=353)$

\begin{tabular}{lll}
\hline Variable & Mean (SD), median & $\boldsymbol{n}(\%)$ \\
\hline Opioid use trajectory ${ }^{1}$ & & \\
Age at first nonmedical PO use & $16.5(3.0), 16$ & \\
Age at first heroin use & $19.1(3.5), 19$ & \\
Age at first heroin injection & $20.4(3.7), 20$ & \\
Age at first PO injection & $20.6(3.6), 20$ & $26(7)$ \\
Drug used at first injection & & $289(82)$ \\
POs & & $14(4)$ \\
Heroin & & $24(7)$ \\
Crack & & \\
Other & & \\
Number of months injected & & $261(74)$ \\
POs regularly ${ }^{2}$ (lifetime) & & $48(14)$ \\
0 months & & $29(8)$ \\
1-12 months & & $15(4)$
\end{tabular}

Number of months injected heroin regularly ${ }^{2}$ (lifetime)

$$
\begin{aligned}
& 0 \text { months } \\
& 1-12 \text { months } \\
& 13-36 \text { months } \\
& >36 \text { months }
\end{aligned}
$$

$34.5(34.9), 24$

Number of days injected POs in the past 30 days

$$
\begin{aligned}
& 0 \text { days } \\
& 1-7 \text { days } \\
& 8-15 \text { days } \\
& >15 \text { days }
\end{aligned}
$$

Number of days injected heroin in the past 30 days

$$
\begin{aligned}
& 0 \text { days } \\
& 1-7 \text { days } \\
& 8-15 \text { days } \\
& >15 \text { days }
\end{aligned}
$$

$5.0(16.0), 0$

$$
\begin{aligned}
& 304(86) \\
& 32(9)
\end{aligned}
$$

18.6 (11.6), 20

$$
56(16)
$$

Type of opioid injected in the past 30 days

\begin{tabular}{ll} 
Heroin only & $251(71)$ \\
POs only & $3(1)$ \\
Heroin and POs & $46(13)$ \\
Neither heroin nor POs & $53(15)$ \\
\hline
\end{tabular}

This table is based on the 353 participants who reported ever injecting drugs ${ }^{1}$ Participants who did not inject POs/heroin were not included in the means and standard deviations

2"Regular" injection is defined as injecting 3 or more times per week for at least 1 month 
Table 3 Correlates of HCV antibody-positive serostatus among young adult PWID $(n=347)$

\begin{tabular}{|c|c|c|c|c|c|c|}
\hline & $\mathrm{HCV}-$ & $\mathrm{HCV}+$ & Unadjusted OR (95\% Cl) & OR $\boldsymbol{p}$ value & AOR $(95 \% \mathrm{Cl})$ & AOR $\boldsymbol{p}$ value \\
\hline$N(\%)$ & $264(71)$ & $101(29)$ & - & - & - & - \\
\hline \multicolumn{7}{|l|}{ Injected POs (lifetime) } \\
\hline No & $117(48)$ & $22(22)$ & Ref & Ref & Ref & Ref \\
\hline Yes & $129(52)$ & 79 (78) & $3.26(1.91-5.56)$ & $<0.01$ & $2.28(1.26-4.13)$ & $<0.01$ \\
\hline \multicolumn{7}{|l|}{ Gender } \\
\hline Male & $89(64)$ & $138(68)$ & Ref & Ref & & \\
\hline Female & $50(36)$ & $66(32)$ & $1.01(0.62-1.65)$ & 0.96 & - & - \\
\hline \multicolumn{7}{|l|}{ Race/ethnicity } \\
\hline Latino/a & $46(19)$ & $18(18)$ & Ref & Ref & & \\
\hline White & $181(74)$ & $75(74)$ & $1.06(0.58-1.94)$ & 0.85 & - & - \\
\hline Non-Latino and non-White & $17(7)$ & $8(8)$ & $1.20(0.44-3.27)$ & 0.13 & - & - \\
\hline \multicolumn{7}{|c|}{ Household income growing up (annual) } \\
\hline$\$ 0-50 k$ & $89(38)$ & $36(43)$ & Ref & Ref & & \\
\hline$\$ 51-100 k$ & $79(34)$ & $33(39)$ & $1.03(0.59-1.81)$ & 0.91 & & \\
\hline$>\$ 100 k$ & $65(28)$ & $15(18)$ & $0.57(0.28-1.13)$ & 0.11 & & \\
\hline \multicolumn{7}{|l|}{ Homeless (lifetime) } \\
\hline No & $92(37)$ & $11(11)$ & Ref & Ref & Ref & Ref \\
\hline Yes & $154(63)$ & $89(89)$ & $4.83(2.46-9.52)$ & $<0.01$ & $3.30(1.62-6.71)$ & $<0.01$ \\
\hline \multicolumn{7}{|c|}{ Number people shared syringes (past 12 months) } \\
\hline 0 & $155(67)$ & $45(46)$ & Ref & Ref & Ref & Ref \\
\hline 1 & $59(25)$ & $28(28)$ & $1.64(0.94-2.86)$ & 0.08 & $1.16(0.61-2.18)$ & 0.65 \\
\hline 2 or more & $18(8)$ & $26(26)$ & $4.98(2.50-9.88)$ & $<0.01$ & $2.16(0.96-4.87)$ & 0.06 \\
\hline \multicolumn{7}{|c|}{ Number people shared cookers (past 12 months) } \\
\hline 0 & $108(47)$ & $24(24)$ & Ref & Ref & Ref & Ref \\
\hline 1 & $53(23)$ & $17(17)$ & $1.44(0.72-2.92)$ & 0.31 & $1.38(0.63-3.02)$ & 0.41 \\
\hline 2 or more & $70(30)$ & $58(59)$ & $3.73(2.12-6.55)$ & $<0.01$ & $2.52(1.31-4.83)$ & $<0.01$ \\
\hline
\end{tabular}

Sample total is 347 instead of 353 because 6 participants did not respond to the series of questions regarding PO injection

omnibus $p$ value of $<0.25(p=0.10)$. In multivariable logistic regression, compared to growing up in lowincome households, PO injection was significantly correlated with growing up in middle- (AOR 1.86, 1.07-3.21, $p=0.03$ ), or high-income households (AOR 2.54, 1.354.76, $p<0.01)$. PO injection was also associated with lifetime homelessness (AOR 2.93, 1.75-4.91, $p<0.01$ ).

\section{Discussion}

This paper provides a qualitative description of the PO injection practices of young PWID in NYC. Qualitative interview findings reveal that $\mathrm{PO}$ injection often necessitates the use of $1.0 \mathrm{cc}$ syringes or the administration of multiple injections with smaller syringes $(0.5 \mathrm{cc})$ due to the additional water that is needed to dissolve extendedrelease and/or abuse-deterrent opioid pills in aqueous solution. These multi-step pill injection practices can increase the likelihood of sharing and cross-contaminating injection equipment, thereby increasing the risk of HIV [29] and HCV transmission [6, 28, 30]. Our findings corroborate results from other qualitative studies that describe the unique mechanics involved in preparing and injecting POs $[8,11]$. By contrast, the mechanics required to prepare and inject heroin-particularly, the powder form of heroin that predominates in the Eastern part of the USA - are considerably less cumbersome, and consequently, intrinsically less risky. The nominal amount of residue that remains in cookers after episodes of heroin injection reduces the likelihood that PWID will be motivated to consume or share "rinse shots," as was reported by study's participants in reference to injecting POs, as well as by Bruneau et al. and Broz et al. [7, 11].

Quantitative results indicate that, in addition to injecting heroin, a majority of young PWID in our sample (59\%) have also injected POs. The prevalence of PO injection, however, is considerably lower than the $75 \%$ reported by Bruneau et al. in Montreal and the $89 \%$ reported by Havens et al. in rural Appalachia [3, 7]. The lower prevalence of PO injection in our NYC sample might be explained by regional differences in drug 
Table 4 Correlates of non-fatal overdose among young adult PWID $(n=340)$

\begin{tabular}{|c|c|c|c|c|c|c|}
\hline & Never overdosed & Overdosed at least once & Unadjusted OR (95\% Cl) & OR $\boldsymbol{p}$ value & AOR $(95 \% \mathrm{Cl})$ & AOR $\boldsymbol{p}$ value \\
\hline$N(\%)$ & $146(43)$ & $194(57)$ & - & - & - & - \\
\hline \multicolumn{7}{|l|}{ Injected POs (lifetime) } \\
\hline No & $80(55)$ & $57(29)$ & Ref & Ref & Ref & Ref \\
\hline Yes & $66(45)$ & $137(71)$ & $2.91(1.86-4.56)$ & $<0.01$ & $2.51(1.53-4.11)$ & $<0.01$ \\
\hline \multicolumn{7}{|l|}{ Gender } \\
\hline Male & $97(67)$ & $124(65)$ & Ref & Ref & & \\
\hline Female & $47(33)$ & $68(35)$ & $1.13(0.72-1.79)$ & 0.60 & - & - \\
\hline \multicolumn{7}{|l|}{ Race/ethnicity } \\
\hline Latino/a & $33(23)$ & $29(15)$ & Ref & Ref & & \\
\hline White & $101(70)$ & $151(78)$ & $1.70(0.97-2.98)$ & 0.06 & - & - \\
\hline Non-Latino/non-White & $11(8)$ & $13(7)$ & $1.34(0.52-3.46)$ & 0.54 & - & - \\
\hline \multicolumn{7}{|c|}{ Household income growing up (annual) } \\
\hline$\$ 0-50 k$ & $61(45)$ & $63(36)$ & Ref & Ref & & \\
\hline$\$ 51-100 k$ & $48(35)$ & $60(35)$ & $1.21(0.72-2.03)$ & 0.47 & & \\
\hline$>\$ 100 k$ & $28(20)$ & $50(29)$ & $1.73(0.97-3.09)$ & 0.06 & & \\
\hline \multicolumn{7}{|l|}{ Homeless (lifetime) } \\
\hline No & $53(36)$ & $47(24)$ & Ref & Ref & Ref & Ref \\
\hline Yes & $93(64)$ & $146(76)$ & $1.77(1.10-2.84)$ & 0.02 & $1.10(0.65-1.85)$ & 0.73 \\
\hline \multicolumn{7}{|c|}{ Number people shared syringes (past 12 months) } \\
\hline 0 & $96(70)$ & $98(52)$ & Ref & Ref & Ref & Ref \\
\hline 1 & $33(24)$ & $54(29)$ & $1.60(0.96-2.69)$ & 0.07 & $1.21(0.68-2.15)$ & 0.51 \\
\hline 2 or more & $8(6)$ & $35(19)$ & $4.29(1.89-9.71)$ & $<0.01$ & $2.25(0.87-5.82)$ & 0.09 \\
\hline \multicolumn{7}{|c|}{ Number people shared cookers (past 12 months) } \\
\hline 0 & $69(51)$ & $57(30)$ & Ref & Ref & Ref & Ref \\
\hline 1 & $33(24)$ & $37(20)$ & $1.36(0.76-2.44)$ & 0.31 & $1.34(0.71-2.55)$ & 0.37 \\
\hline 2 or more & $34(25)$ & $93(50)$ & $3.31(1.96-5.61)$ & $<0.01$ & $2.50(1.39-4.50)$ & $<0.01$ \\
\hline
\end{tabular}

Sample total is 340 instead of 353 because 6 participants did not respond to the questions regarding PO injection and 7 additional participants did not respond to the questions regarding overdose

markets. Heroin in NYC is widely available and significantly cheaper than diverted POs, allowing PWID to choose between POs and heroin based on their incomegenerating strategies and SES, whereas in Canada [29], heroin is available but more expensive than POs, and in certain rural areas of the USA, like Kentucky [3], heroin is difficult to access, which can necessitate more frequent PO injection, even in places where POs are exceedingly expensive (e.g., Scott County, Indiana).

Our qualitative findings illustrate how the preparation and injection practices associated with the parenteral administration of POs (e.g., multiple drug washes, reuse of drug paraphernalia containing drug residue, multiple injections per injection episode) place PWID at increased risk for blood-borne infection. Adjusted odds ratios from multivariable analysis indicate that participants who tested HCV antibody-positive had 2.3 times the odds of having injected POs than those who had never injected them. These results support similar findings reported in both urban [4, 7] and non-urban settings [3, 6]. Taken together, our research findings from NYC contribute to an emerging body of literature indicating that PO injection is independently associated with increased risk of $\mathrm{HCV}$ infection. This heightened risk may explain, in part, the sharp increase in acute HCV infections in many jurisdictions throughout the USA where PO injection is prevalent [31]. It also raises the possibility of an HIV outbreak driven by sharing injection paraphernalia other than syringes when PWID reinsert their own used needle into the cooker in preparation of multiple washes [32]. Additionally, to the extent that PO injection motivates PWID to re-use drug-residue-containing filters or cottons, it could potentially heighten risk for endocarditis, as damp filters provide an ideal breeding ground for bacteria.

In this paper, we also contrast patterns of heroin and PO injection among young adult PWID in NYC. In a drug market with a steady heroin supply, such as NYC, 
Table 5 Correlation between sociodemographics and lifetime PO injection among young adult PWID $(n=347)$

\begin{tabular}{|c|c|c|c|c|c|c|}
\hline & Never injected POs & Ever injected POs & Unadjusted OR (95\% CI) & OR $\boldsymbol{p}$ value & AOR $(95 \% \mathrm{Cl})$ & AOR $\boldsymbol{p}$ value \\
\hline$N(\%)$ & $139(40)$ & $208(60)$ & - & - & - & - \\
\hline \multicolumn{7}{|l|}{ Gender } \\
\hline Male & $89(64)$ & $138(68)$ & Ref & Ref & & \\
\hline Female & $50(36)$ & $66(32)$ & $0.85(0.54-1.34)$ & 0.49 & - & - \\
\hline \multicolumn{7}{|l|}{ Race/ethnicity } \\
\hline Latino/a & $27(19)$ & $37(18)$ & Ref & Ref & & \\
\hline White & $97(70)$ & $159(77)$ & $1.20(0.69-2.09)$ & 0.53 & - & - \\
\hline Non-Latino and non-White & $15(11)$ & $10(5)$ & $0.49(0.19-1.25)$ & 0.13 & - & - \\
\hline \multicolumn{7}{|c|}{ Household income growing up (annual) } \\
\hline$\$ 0-50 k$ & $62(48)$ & $63(34)$ & Ref & Ref & Ref & Ref \\
\hline$\$ 51-100 k$ & $43(33)$ & $69(37)$ & $1.58(0.94-2.65)$ & 0.08 & $1.89(1.10-3.26)$ & 0.02 \\
\hline$>\$ 100 k$ & $25(19)$ & $55(29)$ & $2.17(1.20-3.90)$ & 0.01 & $2.74(1.45-5.06)$ & $<0.01$ \\
\hline \multicolumn{7}{|l|}{ Homeless (lifetime) } \\
\hline No & $56(40)$ & $47(23)$ & Ref & Ref & Ref & Ref \\
\hline Yes & $83(60)$ & $160(77)$ & $2.30(1.44-3.67)$ & $<0.01$ & $2.85(1.71-4.74)$ & $<0.01$ \\
\hline
\end{tabular}

Sample total is 347 instead of 353 because 6 participants did not respond to the questions regarding PO injection

the preponderance of young PWID in this study initiated their opioid use with oral intake of POs at about 16 years old. Oral consumption of POs occurred for an average of 2-3 years prior to the first heroin use at age 19 . Despite years of nonmedical PO use without heroin, a large majority of PWID (82\%) chose heroin as their first injected drug. In sharp contrast to the reported $62 \%$ of PWID in rural Appalachia who initiated injection with POs [3], only 7\% of young PWID in our sample chose POs as their first injected drug. This geographic variation may indicate that in areas where both heroin and POs are readily accessible, opioid users are far more likely to choose heroin instead of POs as the first drug they inject. This might also result from wanting to avoid the complicated hassle of preparing PO for injection.

Despite the predominance of heroin as the drug of choice for initiating injection, a majority of participants (59\%) did report ever having injected POs, indicating a significant prevalence of $\mathrm{PO}$ injection even in an urban location with a well-established heroin market. The widespread availability of heroin in NYC, however, appears to influence the frequency with which participants reported injecting POs relative to heroin. Although many participants had experimented with injecting POs, it was not often a regular practice: only $26 \%$ of respondents reported regular PO injection for at least 1 month (vs. 89\% who reported regular heroin injection). On average, these young PWID, who ranged in age from 18 to 29 years old, reported having injected heroin regularly for 2.8 yearsabout 2 years longer than their reported average duration of regular PO injection (0.8 years). Similarly, when considering the number of days participants reported injecting
POs vs. heroin in the past 30 days, heroin was injected far more frequently: $84 \%$ reported having injected heroin in the past 30 days, for an average of 18.6 days, while only $14 \%$ report having injected POs in the past 30 days, for an average of only 5 days. Nevertheless, the high prevalence of occasional PO injection still poses significant health risks for PWID.

Analyses presented here also indicate that PO injection is significantly correlated with lifetime experience of non-fatal overdose. Similar to other studies [14, 15], our bivariable results indicate a strong correlation between PO injection and overdose. In contrast to these previous studies, however, the association of overdose with PO injection in the current study remained significant in the multivariable model, suggesting a robust association in this sample of young New Yorkers who inject drugs. There are several possible explanations for the observed relationship between PO injection and overdose. On the one hand, PO injectors in this sample are more likely to have grown up in middle- or upper-income families; ergo, they may have more money to spend on opioids and other drugs, which may allow for higher drug intake or polysubstance use, thereby contributing to increased overdose risk. PO injection could also be serving as a marker for a subset of youth who engage in a range of high-risk drug-use behaviors, including behaviors, such as binging on drugs and/or engaging in polysubstance use, that are known to increase risk of overdose.

PO injection was also correlated with having been raised in a higher-income household. This association may possibly reflect the ability of people with higher incomes to continue purchasing POs while concurrently 
using heroin, which tends to occur in drug contexts where heroin is cheaper and easier to access than POs [20]. Yet, to complicate matters, findings also indicate that lifetime homelessness is significantly correlated with PO injection. This may show that different subsets of the population of young PWID in NYC may be engaging in the injection of multiple drugs [4].

This study has some limitations, particularly pertaining to the use of self-reported and cross-sectional data. Participants' ability to recall past events and behaviors, including those that may have occurred years prior, is unknown. There is also the possibility that self-reported data is susceptible to social desirability bias, especially given the sensitive and stigmatized topic of illicit drug use. Because of the cross-sectional nature of the data, our findings cannot establish causation, only correlation. Additionally, as this sample was comprised entirely of young adults who live in NYC, results may not generalize to other populations, especially those in non-urban areas. The use of a nonrandom recruitment strategy-respondent-driven sampling-may also have introduced bias into the sample that limits the generalizability of the findings. An additional limitation in the qualitative data is participants' imprecise description of the pills used for injection, thus limiting our ability to determine which preparation methods are most common to specific PO formulations (regular extendedrelease and/or abuse-deterrent).

Study results illustrate the need for harm reduction strategies to address the specific health risks, particularly with regard to $\mathrm{HCV}$ transmission, posed by the injection of POs. Knowledgeable people who use drugs, prevention projects and agencies should explicitly inform PWID of the increased viral transmission risk associated with PO injection practices and how to mitigate such risk, mainly by always using new, sterile equipment for every injection, and avoiding the sharing of any injection paraphernalia (syringes, cookers, filters, diluting water, and water containers), even if it contains drug residue. In group injection situations where people are doing multiple injections per injection episode, it can be very difficult to avoid accidental cross-contamination. If there is any sharing or splitting of drug solution from a communal cooker, then all PWID involved need to use a sterile syringe for each injection. In situations where individuals will be re-using their own syringes for repeated injections, all those involved in the group injection should mix their own drugs in their own cooker. If larger syringes are to be used, those with detachable needles should never be used, as they hold a larger amount of residual blood and therefore increase the risk of transmitting HCV or HIV [33]. If sharing POs and injecting, users should try to split the pill before breaking it down for injection, with each individual using exclusively their own injection equipment. Recent research suggests that heating a PO-containing drug solution until boiling reduces the risk of HIV transmission [32]; the extent to which this procedure may protect against $\mathrm{HCV}$ transmission is yet unknown but warrants future research.

In summary, these results suggest that a high proportion of young PWID in NYC have injected POs, although it appears to be less frequent than heroin injection. Further, lifetime experience of non-fatal overdose and HCV antibody-positive serostatus were independently associated with having ever injected POs. Existing harm reduction efforts should inform PWID of the increased risks associated with injecting POs and tailor harm reduction messages to address the risky practices associated with preparing and injecting POs, including multiple injections per injection episode and the re-use of drug residue-containing cookers and filters.

\section{Abbreviations \\ PO: Prescription opioid; PWID: People who inject drugs; NYC: New York City; HIV: Human immunodeficiency virus; HCV: Hepatitis C virus; \\ RDS: Respondent-driven sampling; IR: Immediate release}

\section{Acknowledgements}

We would like to thank all the individuals who participated in this study and to Courtney Ciervo for preparing the manuscript for final submission.

\section{Authors' contributions}

PMG developed the interview guide, conducted the interviews, and wrote the first draft of the manuscript. HG and PMG developed the quantitative survey. JT and CF ran the statistical analysis. EG, HG, and PMG contributed to the qualitative analysis. EG and CS contributed to the background information and literature review. PMG, HG, JZ, JT, EG, BE, CS, and SF contributed to the analysis and the writing of the manuscript. BE and SF wrote various drafts of the manuscript and provided key contributions for analysis and discussion. All authors approved of the last version of the manuscript.

\section{Funding}

This research was supported by the National Institutes of Health $(\mathrm{NIH})$ / National Institute on Drug Abuse (NIDA), Grants No. R01DA035146 and R01DA041501. The content is the sole responsibility of the authors and does not necessarily reflect the official views of NIDA or $\mathrm{NIH}$.

\section{Availability of data and materials}

All data generated or analyzed during this study are unavailable due to the presence of identifiers.

\section{Ethics approval and consent to participate}

This study was approved by the National Development \& Research Institutes, Inc. Internal Review Board.

\section{Consent for publication}

Not applicable

\section{Competing interests}

The authors declare that they have no competing interests.

\section{Author details}

${ }^{1}$ CUNY Graduate School of Public Health and Health Policy, Institute for Implementation Science in Population Health (ISPH), 55 West 125th Street, New York, NY 10027, USA. ${ }^{2}$ RTI International, 2987 Clairmont Road, Century Plaza 1, Suite 400, Atlanta, GA 30329-4434, USA. ${ }^{3}$ National Development Research Institutes, Inc., 71 West 23rd St, New York, NY 10010, USA.

${ }^{4}$ Independent Consultant, New York, NY, USA. ${ }^{5}$ NYU School of Medicine, 550 First Avenue, New York, NY 10016, USA. 
Received: 10 January 2020 Accepted: 13 March 2020

Published online: 30 March 2020

\section{References}

1. Jones CM. Trends and key correlates of prescription opioid injection misuse in the United States. Addict Behav. 2018;78:145-52.

2. Jones CM, Christensen A, Gladden RM. Increases in prescription opioid injection abuse among treatment admissions in the United States, 20042013. Drug Alcohol Depend. 2017;176:89-95.

3. Havens JR, Lofwall MR, Frost SDW, Oser CB, Leukefeld CG, Crosby RA. Individual and network factors associated with prevalent hepatitis $C$ infection among rural appalachian injection drug users. Am J Public Health. 2013;103(1):e44-52.

4. Lankenau S, Kecojevic A, Silva K. Associations between prescription opioid injection and hepatitis $C$ virus among young injection drug users. Drugs. 2015;22(1):35-42

5. Conrad C, Bradley HM, Broz D, Buddha S, Chapman EL, Galang RR, et al. Community outbreak of HIV infection linked to injection drug use of oxymorphone_-Indiana, 2015. MMWR Morb Mortal Wkly Rep. 2015;66(3):443-4

6. Zibbell JE, Hart-Malloy R, Barry J, Fan L, Flanigan C. Risk factors for HCV infection among young adults in rural New York who inject prescription opioid analgesics. Am J Public Health. 2014;104(11):2226-32.

7. Bruneau J, Roy É, Arruda N, Zang G, Jutras-Aswad D. The rising prevalence of prescription opioid injection and its association with hepatitis $C$ incidence among street-drug users. Addiction. 2012;107(7):1318-27.

8. Roy É, Arruda N, Bourgois P. The growing popularity of prescription opioid injection in downtown Montréal: new challenges for harm reduction. Subst Use Misuse. 2011:46(9):1142-50.

9. Lake S, Kennedy MC. Health outcomes associated with illicit prescription opioid injection: a systematic review. J Addict Dis. 2015;35(2):73-91.

10. Hadland SE, Debeck K, Kerr T, Feng C, Montaner JS, Wood E. Prescription opioid injection and risk of hepatitis $C$ in relation to traditional drugs of misuse in a prospective cohort of street youth. BMJ Open. 2014:4(7).

11. Broz D, Zibbell J, Foote C, Roseberry JC, Patel MR, Conrad C, et al. Multiple injections per injection episode: high-risk injection practice among people who injected pills during the 2015 HIV outbreak in Indiana. Int J Drug Policy. 2018:52:97-101

12. Mateu-Gelabert $P$, Guarino $H$. The opioid epidemic and injection drug use: MIPIE and health harms related to the injection of prescription opioids. Int J Drug Policy. 2018:57:130-2.

13. Pabayo R, Alcantara C, Kawachi I, Wood E, Kerr T. The role of depression and social support in non-fatal drug overdose among a cohort of injection drug users in a Canadian setting. Drug Alcohol Depend. 2013;132(3):603-9.

14. Havens JR, Oser CB, Knudsen HK, Lofwall M, Stoops WW, Walsh SL, et al. Individual and network factors associated with non-fatal overdose among rural Appalachian drug users. Drug Alcohol Depend. 2011;115(1-2):107-12.

15. Silva K, Schrager SM, Kecojevic A, Lankenau SE. Factors associated with history of non-fatal overdose among young nonmedical users of prescription drugs. Drug Alcohol Depend. 2013;128(1-2):104-10

16. Fischer B, Brissette $\mathrm{S}$, Brochu S, Bruneau J, el-Guebaly N, Noël L, et al. Determinants of overdose incidents among illicit opioid users in 5 Canadian cities. CMAJ. 2004:171(3):235-9.

17. Kerr T, Fairbairn N, Tyndall M, Marsh D, Li K, Montaner J, et al. Predictors of non-fatal overdose among a cohort of polysubstance-using injection drug users. Drug Alcohol Depend. 2007;87(1):39-45.

18. Jenkins LM, Banta-Green CJ, Maynard C, Kingston S, Hanrahan M, Merrill JO, et al. Risk factors for nonfatal overdose at Seattle-area syringe exchanges. J Urban Health. 2011;88(1):118-28.

19. Jessell L, Mateu-Gelabert P, Guarino H, Vakharia SP, Syckes C, Goodbody E, et al. Sexual violence in the context of drug use among young adult opioid users in New York City. J Interpers Violence. 2015:32(19):2929-54.

20. Mateu-Gelabert P, Guarino H, Jessell L, Teper A. Injection and sexual HIV/HCV risk behaviors associated with nonmedical use of prescription opioids among young adults in New York City. J Subst Abuse Treat. 2015;48(1):13-20.

21. Braun V, Clarke V. Using thematic analysis in psychology. Qual Res Psychol. 2006:3(2):77-101

22. Patton MQ. Qualitative research and evaluation methods. Thousand Oaks: Sage Publications; 2002.

23. Mateu-Gelabert P, Jessell L, Goodbody E, Kim D, Gile K, Teubl J, et al. High enhancer, downer, withdrawal helper: multifunctional nonmedical benzodiazepine use among young adult opioid users in New York City. Int J Drug Policy. 2017:46:17-27.

24. Substance Abuse and Mental Health Services Administration (SAMHSA). Results from the 2010 National Survey on Drug Use and Health: summary of national findings [Internet]. Results from the 2010 National Survey on Drug Use and Health: summary of national findings Rockville, MD: U.S. Dept. of Health and Human Services, Substance Abuse and Mental Health Services Administration, Center for Behaviorial Health Statistics and Quality; 2011 p. 11-4658. Available from: https:// www.samhsa.gov/data/sites/default/files/NSDUHNationalFindingsResults2010web/2k10ResultsRev/NSDUHresultsRev2010.pdf.

25. Altman DG, Bland JM. How to obtain the $P$ value from a confidence interval. BMJ. 2011;343

26. Tsui Jl, Evans JL, Lum PJ, Hahn JA, Page K. Opioid agonist therapy is associated with lower incidence of hepatitis $C$ virus infection in young adult persons who inject drugs. JAMA Internal Med. 2014;174(12):1974.

27. Perlman DC, Jordan AE. The syndemic of opioid misuse, overdose, HCV, and HIV: structural-level causes and interventions. Curr HIV/AIDS Rep. 2018;15(2): 96-112.

28. Corson S, Greenhalgh D, Taylor A, Palmateer N, Goldberg D, Hutchinson S Modelling the prevalence of HCV amongst people who inject drugs: an investigation into the risks associated with injecting paraphernalia sharing. Drug Alcohol Depend. 2013;133(1):172-9.

29. Roy É, Arruda N, Bruneau J, Jutras-Aswad D. Epidemiology of injection drug use. Can J Psychiatry. 2016:61(3):136-44.

30. Hagan H, Thiede H, Weiss NS, Hopkins SG, Duchin JS, Alexander ER. Sharing of drug preparation equipment as a risk factor for hepatitis C. Am J Public Health. 2001;91(1):42-6.

31. Zibbell JE, Asher AK, Patel RC, Kupronis B, lqbal K, Ward JW, et al. Increases in acute hepatitis $C$ virus infection related to a growing opioid epidemic and associated injection drug use, United States, 2004 to 2014. Am J Public Health. 2018:108(2):175-81.

32. Ball L, Venner C, Tirona RG, Arts E, Gupta K, Wiener JC, et al. Heating injection drug preparation equipment used for opioid injection may reduce HIV transmission associated with sharing equipment. J Acquir Immune Defic Syndr. 2019:81(4):e127-34

33. Zule WA, Desmond DP, Neff JA. Syringe type and drug injector risk for HIV infection: a case study in Texas. Soc Sci Med. 2002:55(7):1103-13.

\section{Publisher's Note}

Springer Nature remains neutral with regard to jurisdictional claims in published maps and institutional affiliations.

Ready to submit your research? Choose BMC and benefit from:

- fast, convenient online submission

- thorough peer review by experienced researchers in your field

- rapid publication on acceptance

- support for research data, including large and complex data types

- gold Open Access which fosters wider collaboration and increased citations

- maximum visibility for your research: over $100 \mathrm{M}$ website views per year

At $\mathrm{BMC}$, research is always in progress.

Learn more biomedcentral.com/submission 